University for Business and Technology in Kosovo

UBT Knowledge Center

UBT International Conference

2016 UBT International Conference

Oct 28th, 9:00 AM - Oct 30th, 5:00 PM

\title{
Urban landscape and functionality of urban space through the river flow -study cases Berati (Albania) and Gjakova (Kosova)
}

\author{
Binak Beqaj \\ University for Business and Technology, bbeqaj@ubt-uni.net \\ Florian Nepravishta \\ University for Business and Technology, f_nepravishta@yahoo.com
}

Follow this and additional works at: https://knowledgecenter.ubt-uni.net/conference

Part of the Architecture Commons

\section{Recommended Citation}

Beqaj, Binak and Nepravishta, Florian, "Urban landscape and functionality of urban space through the river flow -study cases Berati (Albania) and Gjakova (Kosova)" (2016). UBT International Conference. 69. https://knowledgecenter.ubt-uni.net/conference/2016/all-events/69

This Event is brought to you for free and open access by the Publication and Journals at UBT Knowledge Center. It has been accepted for inclusion in UBT International Conference by an authorized administrator of UBT Knowledge Center. For more information, please contact knowledge.center@ubt-uni.net. 
Urban landscape and functionality of urban space through the river flow -study cases Berati (Albania) and Gjakova (Kosova)

\title{
Urban landscape and functionality of urban space through the river flow -study cases Berati (Albania) and Gjakova (Kosova)
}

\author{
Binak Beqaj, Florian Nepravishta \\ UBT - Higher Education Institution, Lagjja Kalabria, 10000 p.n., \\ Prishtine, Kosovo \\ bbeqaj@ubt-uni.net, f_nepravishta@yahoo.com
}

\section{Study Case Gjakova (river "Krena")}

The city of Gjakova and its location have specific geographical position, especially based on geomorphological characteristics and river flow of different rivers through the city urban area (Krena, Ereniku, Llukaci ...), in this way creating specific urban values which are not well designed and used in the function of community interests towards new identity of the city, in the contrary those can be considered as an urban problem.

For study analyses in this case is considered the segment of river "Krena" in the south-western part of the city of Gjakova, starting from point (1) the bridge of the road "9-1" to the point (2) bridge "Sefedin Xerxa", with a distance of $611 \mathrm{~m}$, while this riverbed was reconstructed along two river sides with some surfaces not urbanized even those are integrated parts of the city center (as it can be seen from Fig.1.) This area divides the city into two parts, old part identified with build area "Çarshia e madhe" and new part identified with area "Qendra e qytetit", and through urban renovation it can be transformed to the element that unifies those two city main areas.

Those two main areas, have differences: architectural, urban, traffic, housing; adding some additional functions in relation with the citizen's needs and requests. Starting from point (1) the main bridge, connecting both sides through traffic flow (automotive, cyclist and pedestrian), while at the end of this segment there is point (2), the bridge with non-adequate dimensions, also connecting two city sides, but, with limitations. In both cases (points (1) and (2)), there is lack of adequate traffic standardized infrastructure (parking spaces, greenery... why not also tram-line?!) in relation with multi-functionality of area. 
Book of Proceedings

International Conference on Architecture and Spatial Planning

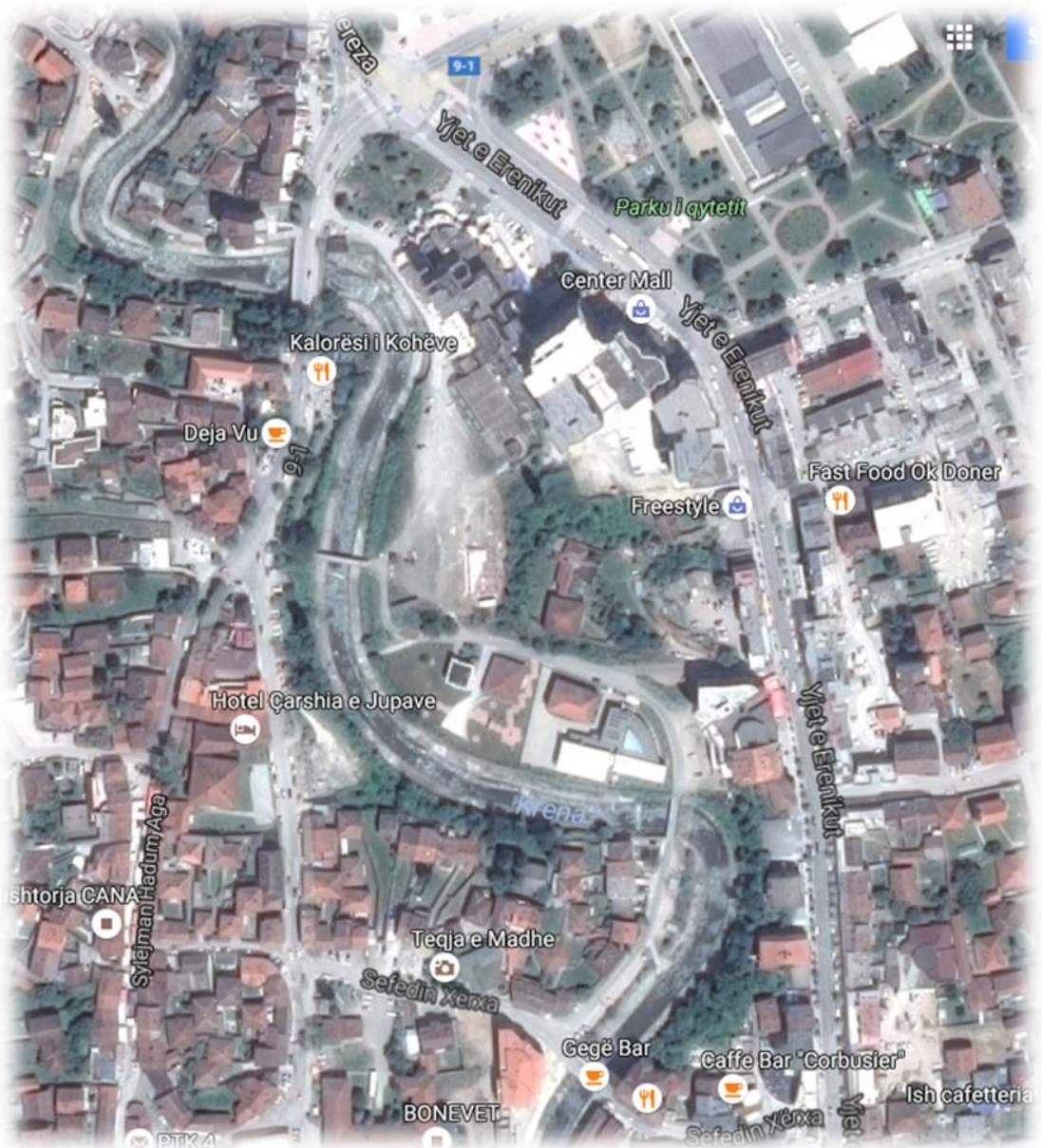

Fig.1. The position of treated segment of river "Krena" in Gjakova (source: Google Earth)

The study work done (during May 2016), using comparative analyses and data's from the field; also interviewing different groups of citizens (more than 300 direct interviews) in relation with their opinions about urban/architectural developments in this area based on their needs and requests. Collected data and information's have been systemized, compared, evaluated and presented (as it can be seen at Fig.2). Some of questions raised during study work are:

- Attendance of citizens in this area

- Proposals for area urban-redestination

- Position of river flow in relation with pollution and degradation during the seasons of the year 
Urban landscape and functionality of urban space through the river flow -study cases Berati (Albania) and Gjakova (Kosova)

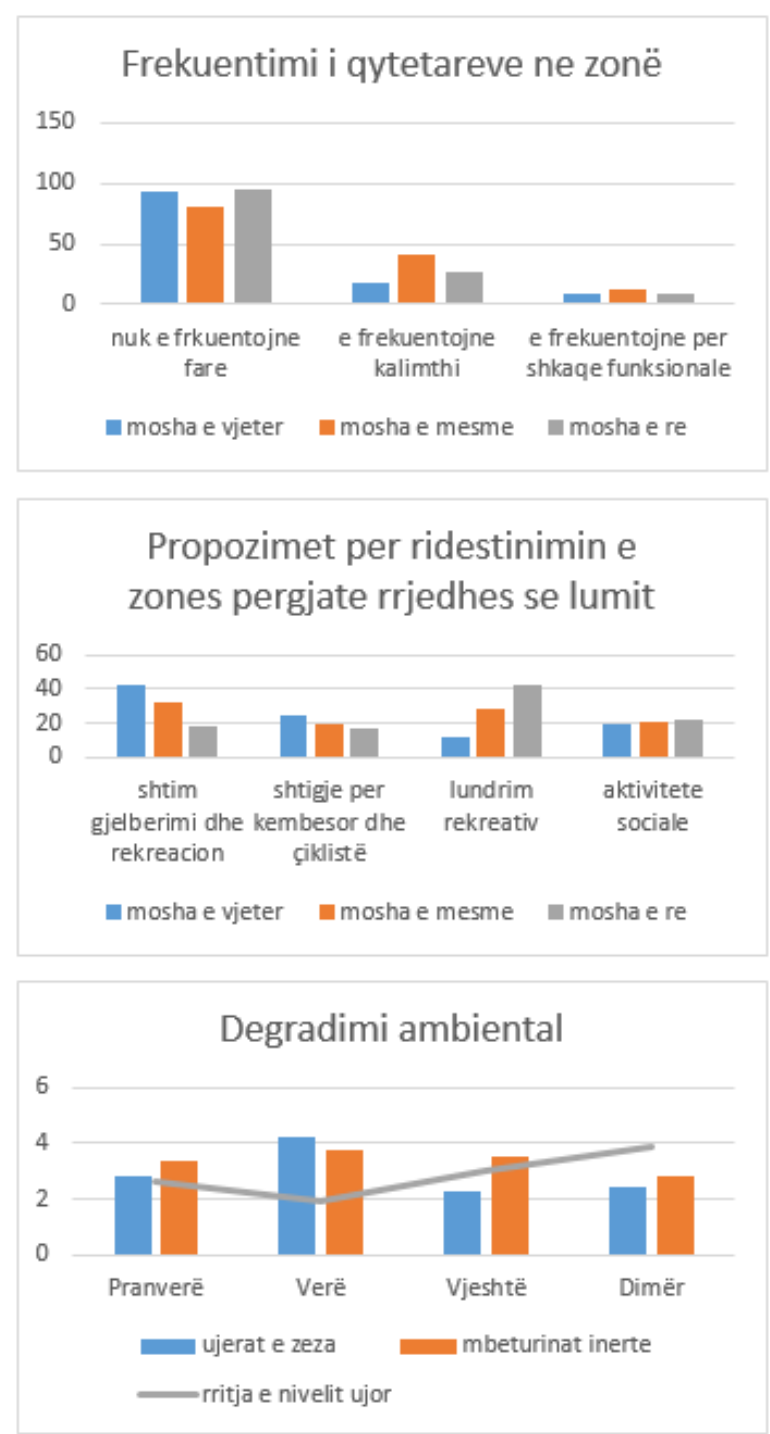

Fig.2. Results about main questions raised in the study (source: study work, May 2016)

Regarding citizens attendance in the area it depends on their different age groups (young age up to 18 years old, medium age up to 50 years old and elders more than 50 years old). From results in general can be seen that this area mostly is not well frequented by the citizens, while medium age are using the area as transit to other parts of the city. 
Book of Proceedings

International Conference on Architecture and Spatial Planning

The main reason why area in most of the time is empty, is because this is not in urban/ architectural way, still not well regulated and dedicated, even that is part of central urban area of the city, so, there is an emergent need for its urban regulatory planning through the concept as multi-functional public urban area adding some spatial/functional values there ( greenery, recreation, pedestrian and cycle paths, recreational sailing with boats, or some more spaces for social activities there like: meetings, manifestations). From the results presented in Fig.2, can be seen that adding more greenery and recreation to area is a request dominated by elders and medium age, while adding more pedestrian, cycle paths and public spaces for social activities there is a request of all age groups. Recreational sailing with boats as a request is dominated form young generation as attractive idea!

The river flow, during the year, is under pollution and degradation, with different intensity as it can be seen in Fig.2, sewage water, waste and level of the water in the river is of different intensity in different seasons of the year. For this environmental problem there is a need that through implementation of approved regulations and technical/technological innovations related to this field, reducing degradation and pollution and making possible that this area to be considered as area with environmental values in the city.

Making regulatory urban planning for this area, can be secured its multi-functional concept, esthetic landscape and transferring this to the referent point of the city, towards ne its urban identity (as presented in Fig.3).
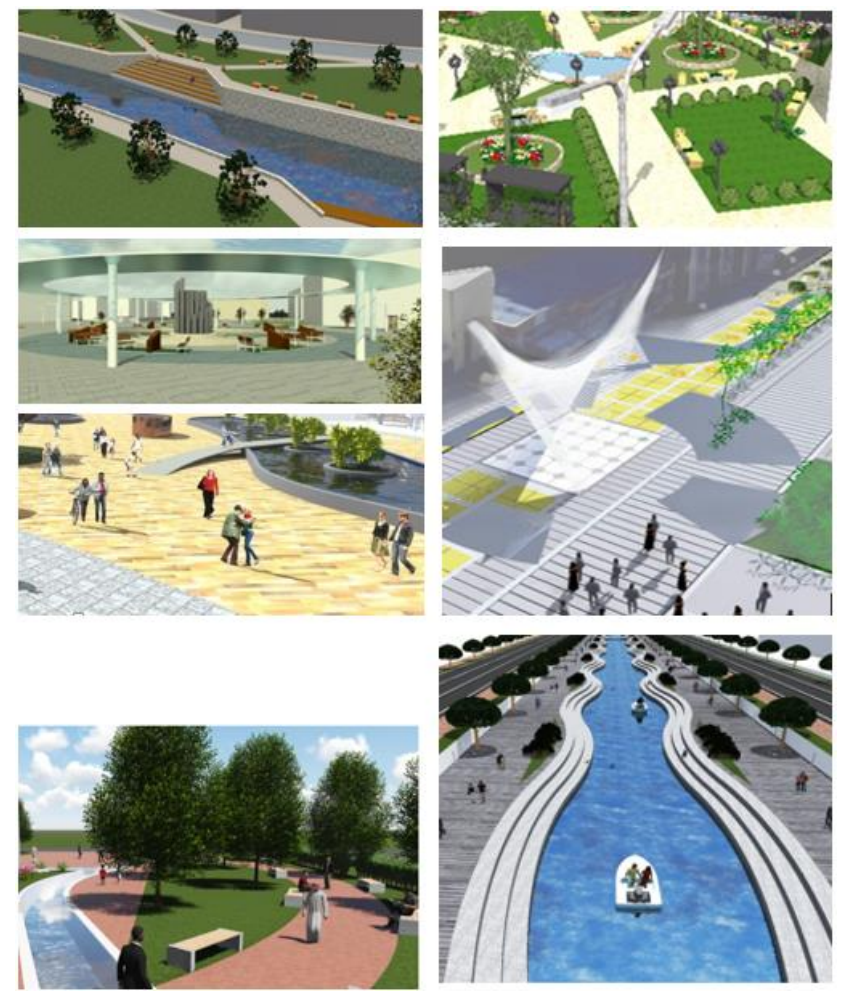
Urban landscape and functionality of urban space through the river flow -study cases Berati (Albania) and Gjakova (Kosova)

Fig.3. Some of the designed proposals of possible urban/architectural solutions for area of river flow "Krena"

\section{Study Case Berati (river "Osumi")}

The city of Berat is initially set as the castle, on the rocky hill at a height $187 \mathrm{~m}$ above sea level, and lies mainly in the right side of the river Osum. Osumi River, one of the main rivers of the country, flows through the city being directed Myzeqe lowlands. It is of interest to agriculture, energy, hydrogeology, ecology and urban planning.

Berat seldom belongs to the cities where life begins in deep antiquity and continues uninterrupted until today. Two stone hammers the beginning of life dating back to before the Bronze Age (2600-1800 BC). Archaeological evidence shows that the century. VII-VI BC here is developing a citizenship inside the town, with its pottery workshops and a differentiated social life. In the margins of legend and history, this settlement is said to have been the ancient Orestiada, named so because there lived a tribe of Pelasgians Oreste, the first of which was Orestes, son of Agamemnon.

The city was founded in 313-310 BC as Dasaretisë castle city, called Antipatrea king in memory of General Cassandra successors of Alexander the Great. This is the first name of the city. After the Roman conquest in the first century. II BC he was called from Oppidum Albanorum (Fortress Arbërve). Century. V under the Byzantine Empire, was reinforced and changed its name to Pulheriopolis (beautiful city). Plagued by Bulgarians century. IX, was called Belgrad (White City) - Berat today.
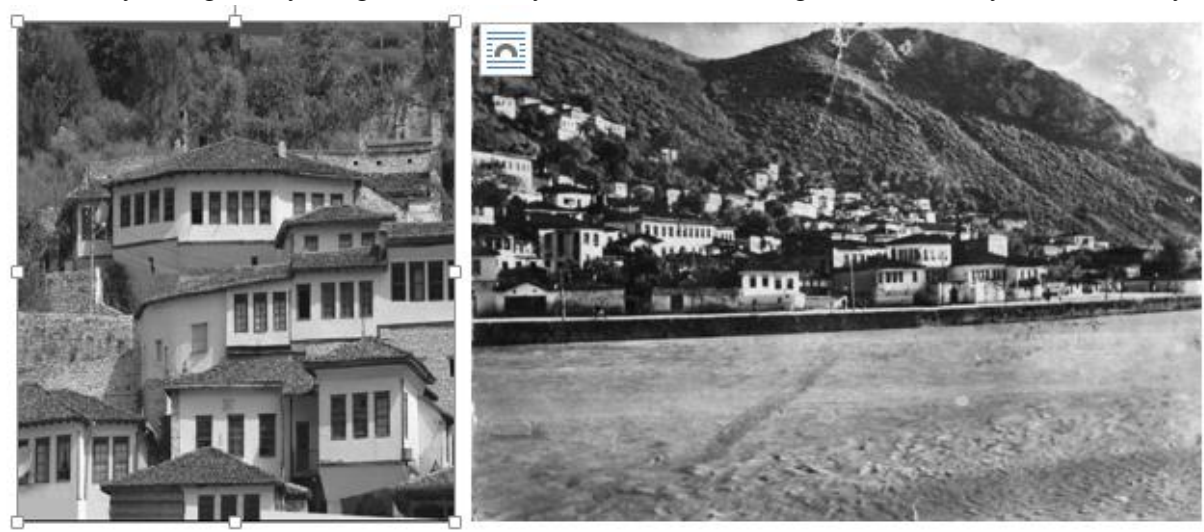

Fig. 4. Historical areas of Mangalem and Gorica

Architecture of Berat mainly from Social buildings, theaters, promenades, Illyrian temples, are evidence of the economic-social-cultural Portland. Their architecture shows for creative applications in both style and we planimetric volumetric format. Steps forward in this time was handling layout, adapting to new schemes by orthogonal system. Berat Castle, the neighborhood "Gorica" and "Mangalem" which are old and prove a thing. The architecture of the fortifications and the planning system were forwarded without interruption from antiquity to the middle Ages, but this time noticed the use of new protective elements, such as fenced yards. At this time, some churches are reviving the existing and construction of several new churches. Ottoman conquest brought a different type of building and architecture of the Islamic cult, but without disconnecting links with tradition, as in 


\section{Book of Proceedings \\ International Conference on Architecture and Spatial Planning}

technical, planimetric conception of typical values in both the architectural details. In the period between XVI-XIX centuries was also raised a series of other churches, rebuilt the castle, fortification poshten ends of kalase.Fillojne social engineering constructions, water taps, pipelines, etc. High Gate charges as responsible architecture and building architect Qasemi. Take off the popular architecture with buildings and ensembles as well as special constructions, urban development, the special character of the buildings and their evolution, make a fortune, which comes down to us with timely intervention. Stages of development of the city, housing and environments, traditional fireplaces, good chambers, the porch, the corner, the road network, sewerage and greenery are part of this development. Rehabilitation of boulevard "Republika" and the "Teodor Muzaka" square next to the rivër The pedestrian area at the boulevard "Republika" and the "Teodor Muzaka" square situatet in Osumi riverfront, funded by the Albanian-American Fund for Development and the Municipality of Berat, are one of the most important urban interventions for the city. The AADF began implementing Berat BID ${ }^{50}$ in October of 2013. As part of "Revival of Cities", a project for the overall regeneration of public spaces is being implemented in Berat, with an investment of 3 million dollars. The revitalization project, aims to liven up the atmosphere and the operation of promenade Republica and the central square Teodor Muzaka for the citizens. It aims to create the first station and the last resort of recreation for tourists flows and providing the necessary infrastructure for the square situated between the river Osum and historical area (the old quarters and Castle of Berat). The four components of the project are infrastructure enhancement, entrepreneurship and business development, creation of the business association and cultural and eco-tourism improvement. The new BID zone will include a Visitor Center which will provide information for tourists on a variety of sites like the Berat Castle, Mangalem, Gorica, Osum Canyons and Tomori Mountain.

Along with rehabilitation works for the promenade area and the main square, with a Government fund $^{51}$, works have been continuing also for the reconstruction of the new river road where decorative gates have being placed according to standards of the museum area. In addition, the west park of the centre is being revitalized.The new road up to the bridge of Gorica, where restorated. The bridge of Gorica, built in 1777, is considered among the city's attractions. Hence, its restoration have maintain the old bridge, by redoing the entire 127-meter long cobblestones over the bridge, cleaning the facade, restoring the damaged parts, installing electrical lines and releasing water supply. Infrastructure work was completed in October 2014 [Available: http://www.aadf.org/project/business-improvementdistricts/berat/].

\footnotetext{
${ }^{50} \mathrm{BIDs}$ are public-private partnerships that are publicly supported, privately managed organizations created to improve the physical environment and enhance public services and investments in urban areas.

${ }^{51}$ Approximately 262.5 million leke [Revival of Berat on the way of implementation. Available:

http://www.kryeministria.al/en/newsroom/news/revival-of-berat-on-the-way-of-implementation]
} 
Urban landscape and functionality of urban space through the river flow -study cases Berati (Albania) and Gjakova (Kosova)
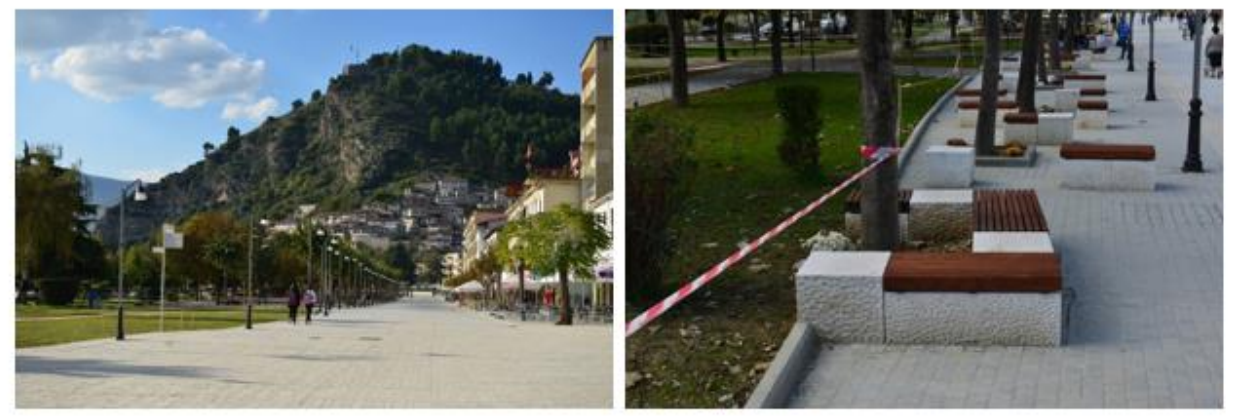

Fig. 5. Rehabilitation of the boulevard "Republika" and the "Teodor Muzaka" square

Osum River Island is a small with a very unique historical context being located near the historic center of Berat which is now part of the cultural heritage funds of UNESCO. The island itself is an area set aside and neglected by the city, but which nevertheless form the shape changes from time to time due to fluctuations of water in the bed of the river Osum. The strong presence of this asset in Berat makes us think that this island can truly transform and turn in the spotlight for the city, but especially for its surrounding areas. On the other hand, along their common history, the island and the water flowing on the banks of the river Osum, they have been constantly 'clash to determine their territories. Although the flood itself is not a new phenomenon, it again finds unprepared residents of areas that become a victim of its continuity as a result again we have a considerable inventory of damages and consequences.

Ideas about connected Island Osumi in Berat with the network of spaces the city of Berat was provided by Atelier Albania at the request of the Municipality of Berat, who in February 2015 announced an international competition to propose the idea of developing landscape values of the island to Osumi in Berat, as well as to find ways to be flexible and to renewable of natural phenomenon. This international calls is looking for ways in which what is called urban can coexist with nature and be both flexible and renewable against every natural phenomenon. Approaching an island doesn't mean to approach a defined fragment of territory. An island is part of the larger organism of the river, and is the river the natural element under our spotlight. The dependence of the Osumi Island to its river is so evident that is not even possible to define the shape of the island, continuously transforming with the varying water levels to the extreme of disappearing. In the proposal start by addressing a more resilient water system that can absorb risks and vulnerabilities and develop its own cultural and recreational identity. Osumi Island is part of it; its context makes the island unique. The UNESCO heritage site and the urban context integrates with the natural system of the river generating all-new range of possible scenarios and a new cultural gravity which is urban, by nature. 
Book of Proceedings

International Conference on Architecture and Spatial Planning
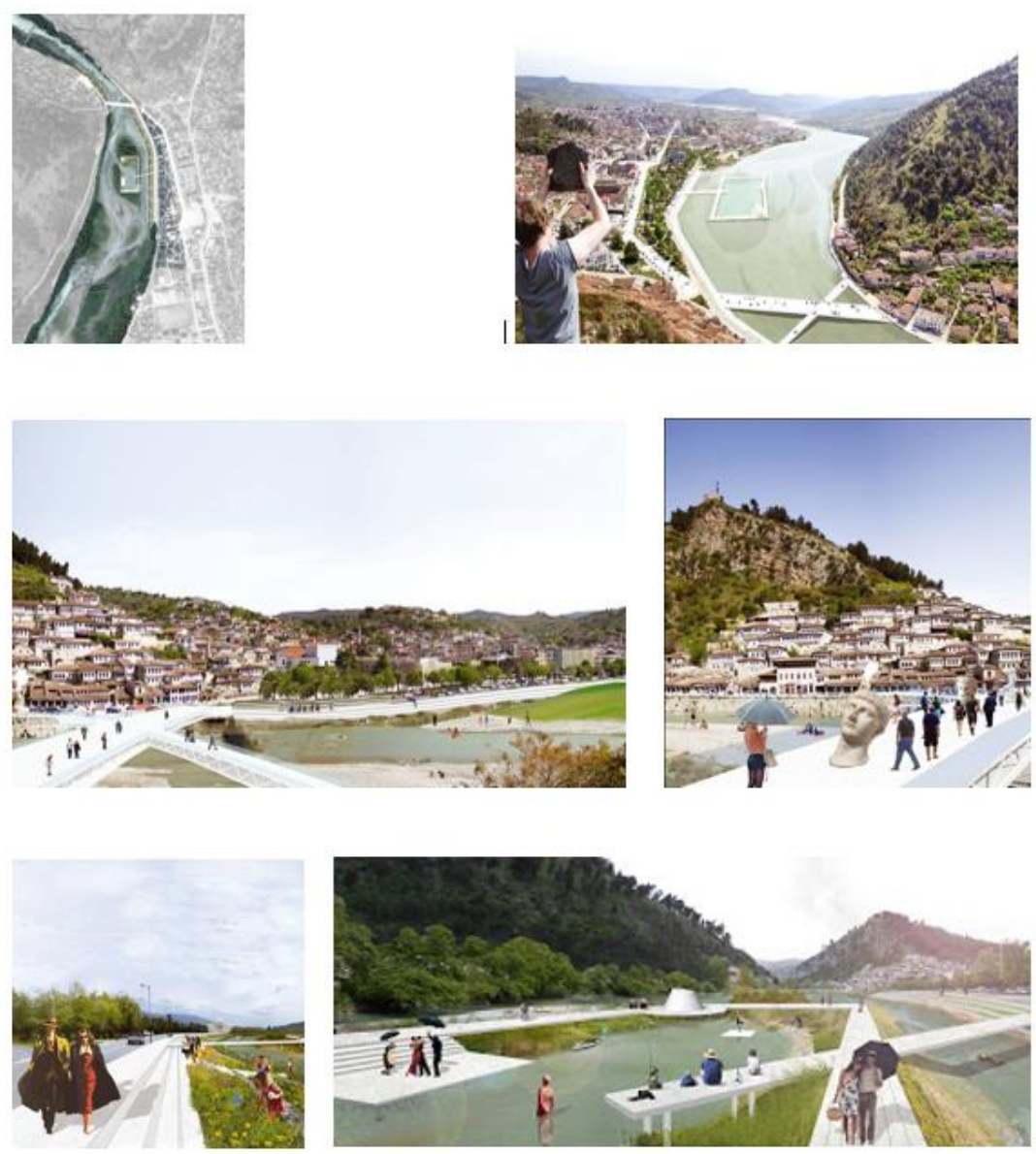

Fig.3. Some of the designed proposals of possible urban/architectural solutions for area of river flow "Osum"

\section{Conclusion}

As explained from both study cases, urban regulatory plan for those areas is not anymore only as option but it is a need, based on community needs but also on need for sustainable urban development of the city in general especially its central part in case of Gjakova, and its peripheral part in case of Berat. Through urban regulatory planning of the river flow, especially with focus on its spatial functionalization through the sides of the river flow, contributing on usefulness of the selected areas through the multi-functional concept, improving landscape too; all this with multiple impacts on: 
Urban landscape and functionality of urban space through the river flow -study cases Berati (Albania) and Gjakova (Kosova)

- New urban identity and character of the city

- Spatial optimization for pedestrians and promotion of the community feeling in the society

- Multifunctional use of different purposes

- Environmental/ ecological improvements

- Aesthetics physic view and good relationship between build and non-build area with its surrounding

- Social aspect, through activities: meetings, meditations, open shows and manifestations

- Integration with other urban units (city parks, city squares, city centers)

- Improvement of public health of community (eviction of pollutions, noises, and physical activities which can be developed there)

- Development of ecosystem and microclimate

- Improvement of security not only in selected areas but for whole city

- Tourism development and economic benefits

\section{References}

1. Charles Montgomery, "Transforming our lives through urban design", (2013)

2. Setha M. Low, Neil Smith, "The politics of public space", (2006)

3. Peter John, "Analyzing public policy”, (2013)

4. Binak Beqaj, "Zhvillimi urban, planifikimi dhe dizajni”, (2015)

5. Jan Gehl, "Life between buildings using public space", (2011)

6. Jan Gehl, "Cities for people", (2010)

7. Ministry for the Environment, Wellington, "The Value of Urban Design. The Economic, Environmental and Social Benefits of Urban Design", (2005)

8. Baltic University Urban Forum, "Built Environment and Revitalization", (2006)

9. John Chang, "The problematization of urban sprawl in the United States", (2006)

10. EU Commission, "Making our Cities Attractive and Sustainable", (2010)

11. World Bank, "Measuring Growth and Change in Metropolitan Form", (2012)

12. World Bank, "Vlerësimi i sektorit urban në Shqipëri”, (2007) 